American Journal of Nanotechnology 1 (2): 78-85, 2010

ISSN 1949-0216

(C) 2010 Science Publications

\title{
Cytotoxicity Studies of Superparamagnetic Iron Oxide Nanoparticles in Macrophage and Liver Cells
}

\author{
${ }^{1}$ Aroonsri Priprem, ${ }^{1}$ Pramote Mahakunakorn, ${ }^{2}$ Chunpen Thomas and ${ }^{2}$ Ian Thomas \\ ${ }^{1}$ Department of Pharmaceutical Technology, Faculty of Pharmaceutical Science, \\ ${ }^{2}$ Department of Physics, Faculty of Science, \\ Khon Kaen University, Khon Kaen, 40002, Thailand
}

\begin{abstract}
Superparamagnetic Iron Oxide Nanoparticles (SPIONs) prepared by simplified coprecipitation were attractive as MRI contrast agents and drug carriers which could internally be manipulated under the influence of an external magnetic field and also cancer treatment due to additional hyperthermia effects. Problem statement: Macrophage and liver cells are potentially exposed to internal SPIONs, thus used for this cytotoxic tests for safety information of SPIONs. Approach: The SPIONs were physicochemically characterized by several instruments to ensure the production process. Cell viabilities, lipid peroxidation and nitric oxide produced after exposure to the SPIONs were conducted in normal macrophage and liver cells. Results: The approximately $15 \mathrm{~nm}$ SPIONs produced had their structure confirmed by FTIR and X-ray diffraction and their magnetic properties probed by NMR. Macrophage and liver cells reacted differently to the SPIONs in dose- and time-dependent manners. Lipid peroxidation increased in macrophage cells, but not liver cells, after $24 \mathrm{~h}$ exposure to $100 \mu \mathrm{g} \mathrm{mL}^{-1}$ of SPIONs, but decreased after $72 \mathrm{~h}$. Pro-inflammatory effect on macrophage cells induced by the SPIONs and measured as nitric oxide was not observed. Concentration of SPIONs up to $25 \mu \mathrm{g} \mathrm{mL}{ }^{-1}$ did not alter cell function and morphology. Conclusion: SPIONs produced by our simplified co-precipitation are dose-dependent cytotoxic to macrophage and liver cells.
\end{abstract}

Key words: Cytotoxic, macrophage cells, liver cells, superparamagnetic iron oxide nanoparticles

\section{INTRODUCTION}

Nanoparticles of metal oxides often exhibit enhanced chemical, thermal, magnetic or biological properties which make them useful particularly in biomedical applications. Magnetic nanoparticles offer some attractive possibilities as they can be internally manipulated under the influence of an external magnetic field (Sun et al., 2008; Shubayev et al., 2009). Single-domain magnetic particles have generated growing interest since their introduction (Papell, 1965), due to their potential use in applications such as contrast agents, biosensors, seals, bearing dampers and lubricants and most recently they have demonstrated a new role in cognitive function in the human brain (Banaclocha et al., 2010). Specialized applications of these magnetic particles impose strict requirements on their characteristics, such as chemical composition, size distribution and uniformity, crystal structure, stability of magnetic properties, surface structure, adsorption properties, solubility and low toxicity (Thorek et al., 2006). Superparamagnetic Iron Oxide Nanoparticles (SPIONs) have been the most extensively investigated due to their excellent biocompatibility and ease of synthesis for multifunctional biomedical applications such as cellular targeting and drug delivery, tissue repair, magnetic resonance imaging and magnetofection (Sun et al., 2008; Shubayev et al., 2009; Thorek et al., 2006; Gupta and Gupta, 2005; Bhaskar et al., 2010). Magnetic targeting particles and carriers have been granted multi-centre Phase I and II clinical trials for hepatocellular carcinomas (Pankhurst et al., 2003). Biodistribution and intracellular delivery of magnetic nanoparticles to target cells is made possible by controlling particle size distribution, particle charge, surface chemistry, shape and microstructure (Sun et al., 2008; Pankhurst et al., 2003). SPIONs are commonly produced via chemical co-precipitation (Molday, 1984; Ma et al., 2003), hydrothermal synthesis (Wang et al., 2003; Xu and Teja, 2008), thermal decomposition (Pei et al., 2007) and electroprecipitaion (Marques et al., 2008). Co-precipitation of ferrous $\left(\mathrm{Fe}^{2+}\right)$ and ferric $\left(\mathrm{Fe}^{3+}\right)$ ions by a base in an aqueous solution under anaerobic conditions is simple, reproducible and efficient. Co-precipitation in a nonaqueous system produces size-controlled monodispersed SPIONs (Sun and Zeng, 2002).

Corresponding Author: Aroonsri Priprem, Department of Pharmaceutical Technology, Faculty of Pharmaceutical Science, Khon Kaen University, Khon Kaen, 40002, Thailand 
Typically, magnetic nanoparticles distribute to the liver $(80-90 \%)$, spleen $(5-8 \%)$ and bone marrow (1$2 \%)$. Their surfaces may interact with extracellular matrix components and the plasma cell membranes of macrophages, endothelial cells, skin epithelium, respiratory depending on the route of administration and particle size (Shubayev et al., 2009). SPIONs are potentially capable to generate Reactive Oxygen Species (ROS) leading to oxidative stress which can be measured by lipid peroxidation. In vitro assays with cells usually employ cells which can model a response or phenomenon likely observed or sensitized by particles in vivo so as to reflect possible physiologic responses to the nanoparticles (Jones and Grainger, 2009). To monitor cytotoxicity of nanoparticles, phagocytic and hepatic cells are commonly used.

The cytotoxicity of SPIONs prepared by a coprecipitation method was investigated in macrophage and liver cells. Lipid peroxidation and nitric oxide, indicators of free radical and pro-inflammatory mediators, respectively, were monitored so as to identify effects of the SPIONs on cell functions.

\section{MATERIALS AND METHODS}

Chemicals: Iron (III) chloride ( $\mathrm{FeCl}_{3}$, Sigma, Germany), iron (II) chloride $\left(\mathrm{FeCl}_{2} \cdot 4 \mathrm{H}_{2} \mathrm{O}\right.$, Sigma, USA), ammonium hydroxide $\left(25 \% \mathrm{NH}_{4} \mathrm{OH}\right.$, Merck, Germany), polysorbate or Tween $80\left(\mathrm{C}_{64} \mathrm{H}_{124} \mathrm{O}_{26}\right.$, Sigma, USA), Dulbecco's Modified Eagle Medium (DMEM, Invitrogen, USA), dimethyl sulfoxide (DMSO, SigmaAldrich, Germany) and 3-(4, 5-dimethylthiazol-2-yl)2,5-diphenyltetrazoliumbromide (MTT, Invitrogen, USA) were purchased and used as received. Greiss reagent was prepared from sulfanilamide (Sigma, USA) and N-1-napthylethylenediamine dihydrochloride (Fluka, Germany).

Synthesis of Superparamagnetic Iron Oxide Nanoparticles (SPIONs): Co-precipitation occurred after heating (up to $160^{\circ} \mathrm{C}$ ) a mixture of equal concentrations (in gram equivalent) of each of freshly prepared solutions of ferrous $\left(\mathrm{Fe}^{2+}\right)$ and ferric $\left(\mathrm{Fe}^{3+}\right)$ ions in deionized water, while thoroughly mixing using a homogenizer (Daihan Scientific, Seoul, Korea) and adjusting the $\mathrm{pH}$ to neutral by adding ammonium hydroxide. Black precipitates of SPIONs, retained through 3 layers of membrane filtration (pore size 0.2 $\mu \mathrm{m})$, were cleaned with deionized water, absolute ethanol and hot air dried at $50^{\circ} \mathrm{C}$.

Preparation of SPIONs for cell exposure: Dried SPIONs were suspended in $0.001 \%$ Tween 80 solution followed by sonication at $24 \mathrm{kHz}$ (Hielscher
Ultrasonics $\mathrm{UH} 50 \mathrm{H}$, Germany) for $30 \mathrm{~min}$, the final concentration being $1 \mathrm{mg} \mathrm{mL}^{-1}$.

\section{Characterization of SPIONs:}

X-Ray powder Diffraction (XRD): Dried SPIONs were crystallographically investigated using an X-ray powder diffractometer (Philips PW 3710, Amelo, The Netherlands), at x-ray wavelength of $0.154 \mathrm{~nm}, 0.2^{\circ}$ step of $2 \theta$ angle. An estimation of average crystallite size of the result was conducted based on Scherrer's line broadening equation, as follows:

$\mathrm{D}=\frac{\mathrm{k} \lambda}{\beta \cos \theta}$

Where:

$\mathrm{D}=$ The crystallite size

$\theta=$ The diffraction angle

$\lambda=$ The $\mathrm{x}$-ray wavelength $(0.15406 \mathrm{~nm}$ being used in this study)

$\beta=$ The full width at half maximum

$\mathrm{K}=$ An instrument constant, i.e., 0.89 in this study

Fourier Transform Infrared (FTIR) spectroscopy: An FTIR spectrophotometer (Perkin Elmer Spectrum One FTIR spectrophotometer, Massachusetts, USA) was used to assay the SPIONs using a wave number range of $400-4000 \mathrm{~cm}^{-1}$.

Nuclear Magnetic Resonance (NMR): NMR spinspin relaxation time $\left(\mathrm{T}_{2}\right)$ of protons $\left({ }^{1} \mathrm{H}\right)$ was measured using an NMR relaxometer (Maran spectrometer, Resonance Instruments (now under Oxford Instruments), Surrey, UK) to monitor the magnetic properties of the nanoparticles in solution at $12.78 \mathrm{MHz}$ and $25^{\circ} \mathrm{C}$. The measurement used the Carr-Purcell Meiboom-Gill (CPMG) pulse sequence (Farrar and Becker, 1971) Care was taken to measure $T_{2}$ with minimal diffusion effects by using the half echo-time (TE/2) values as short as possible. The TE/ 2 values used were in the range of 40-500 $\mu \mathrm{s}$ with 100-4000 echoes. About $0.1 \mathrm{~mL}$ of each sample in a $6 \mathrm{~mm}$ diameter glass tube was used. Each $\mathrm{T}_{2}$ data was averaged from triplicate samples which were homogeneously dispersed while measuring. The spin-spin relaxation rate due to the SPIONs $\left(1 / \mathrm{T}_{2}{ }^{*}\right.$ or $\mathrm{R}_{2}{ }^{*}$ ) was estimated, by the following equation:

$\mathrm{R}_{2}^{*}=\frac{1}{\mathrm{~T}_{2}^{*}}=\frac{1}{\left(\mathrm{~T}_{2}\right)_{\text {sample }}}-\frac{1}{\left(\mathrm{~T}_{2}\right)_{\text {blank }}}$

Morphology: The morphology of the product was observed by Transmission Electron Microscopy (TEM; Jeol JEM 2010, JEOL, Japan). 
Cytotoxicity studies: Cell lines of Chang liver and macrophage, cultured in liquid Dulbecco's Modified Eagle's Medium (DMEM), were plated at a cell density of about 20,000 cells/well of the 24-well plates (Nunclon, Denmark) or 96-well plates (Corning, USA) overnight in a $5 \% \mathrm{CO}_{2}$ incubator (Jencons PLS, RS Biotech, UK) at $37^{\circ} \mathrm{C}$.

Cell viability using MTT (Jones and Grainger, 2009): The cultured cells were exposed to SPIONs at various concentrations and then incubated with MTT $\left(0.5 \mathrm{mg} \mathrm{mL}{ }^{-1}\right)$ for $30 \mathrm{~min}$. The medium was removed and DMSO added to dissolve formazan crystals, the metabolite of MTT and, after thorough mixing, the optical density of each was recorded at 550-750 nm. Cell viability was calculated and expressed as percentage of the control (Wang et al., 2009).

Lipid peroxidation by MalondialdehydeThiobarbituric Acid Reactive Substance (MDATBARS) assay: Malondialdehyde (MDA) content, a measure of lipid peroxidation, was assayed as Thiobarbituric Acid Reactive Substance (TBARS) (Ohkawa et al., 1979). Thiobarbituraic acid was added to the cultured medium, followed by perchloric acid. The mixture was incubated at $95^{\circ} \mathrm{C}$ for $15 \mathrm{~min}$, cooled and centrifuged. The absorbance of the supernatant was measured at $550 \mathrm{~nm}$ and $550-750 \mathrm{~nm}$ using a microplate reader (BioRAD 680, Germany).

Measurement of Nitric Oxide (NO): NO production in cell culture medium was performed by employing Greiss reagent (1\% sulfanilamide, $2.5 \% \mathrm{H}_{3} \mathrm{PO}_{4}, 0.1 \%$ $\mathrm{N}$-1-napthylethylenediamine dihydrochloride). The absorbance at $550 \mathrm{~nm}$ was measured and nitric oxide concentration was determined.

Statistical analysis: Quantitative analysis of the NMR relaxation time of the SPIONs was analyzed by linear regression analysis between concentration of the SPIONs and the $1 / \mathrm{T}_{2}$. ANOVA was used to compare the results obtained from cytotoxicity.

\section{RESULTS}

TEM photographs of SPIONs, Fig. 1, demonstrate clusters of particles with a range of $5-15 \mathrm{~nm}$ in diameter. The clusters were formed by attractive forces between the dispersed magnetic nanoparticles in water. Those with and without polysorbate 80 gave an average size of $11.4 \pm 1.7$ and $8.8 \pm 1.9 \mathrm{~nm}$, as shown in Fig. 1a and $b$, respectively, suggesting that surfactant molecules did coat the surface of the SPIONs.

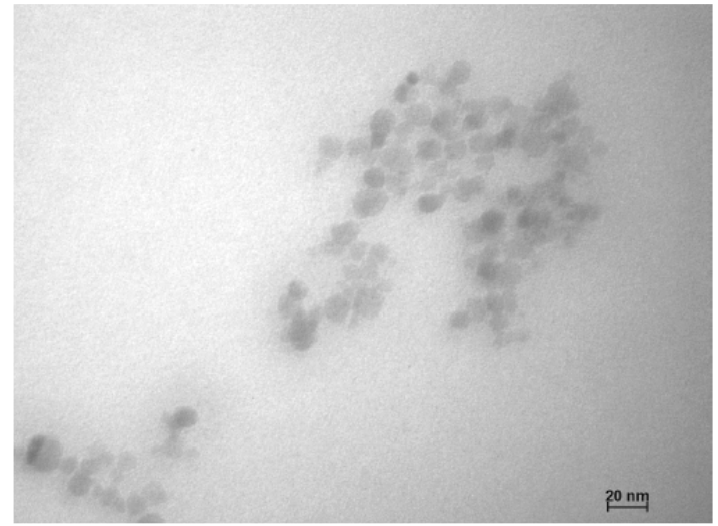

(a)

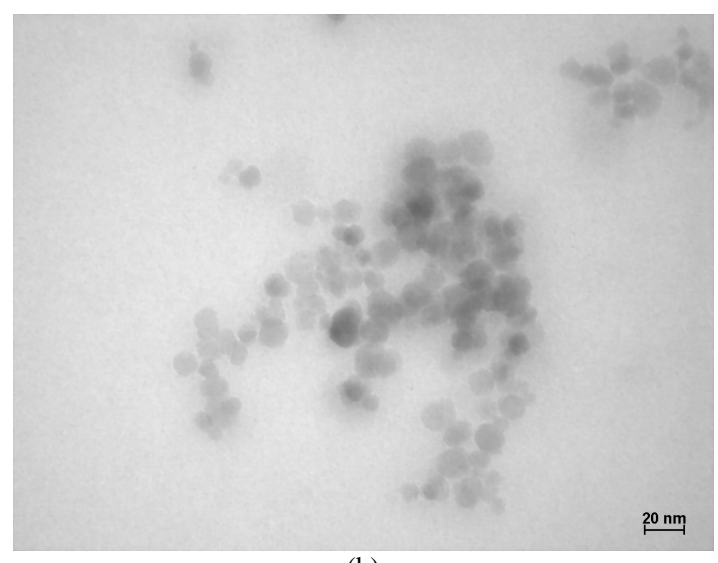

(b)

Fig. 1: Transmission Electron Microscope (TEM) photographs of the SPIONs (a) uncoated and (b) coated with polysorbate 80

An XRD pattern of SPIONs as shown in Fig. 2 demonstrates several peaks from $5-80^{\circ}$. There was no interference from the prominent peaks below $26^{\circ}$ which resulted from the tape used to fix the SPIONs before mounting for analysis. These diffraction peaks at $30.3,35.8,43.4,53.8,57.3,63.1$ and $74.5^{\circ}$ correspond to the respective crystal planes (220), (311), (400), (422), (511), (440) and (533) of a $\mathrm{Fe}_{3} \mathrm{O}_{4}$ crystal with a cubic spinel structure within error of $\pm 0.5^{\circ}$ (according to the PDF-890691, ICSD 082237 database). Calculation of average crystallite size using data from these peaks is based on Scherrer's line broadening equation (Wang et al., 2007). The crystallite size of SPIONS produced was thus calculated as $14 \pm 3 \mathrm{~nm}$, by Eq. 1 .

The FTIR fingerprint of the SPIONs, Fig. 3, shows the strong absorption band at $580 \mathrm{~cm}^{-1}$ of iron and oxide bonding for pure magnetites (Wang et al., 2007), while the $\mathrm{O}-\mathrm{H}$ band comes from water residue. 


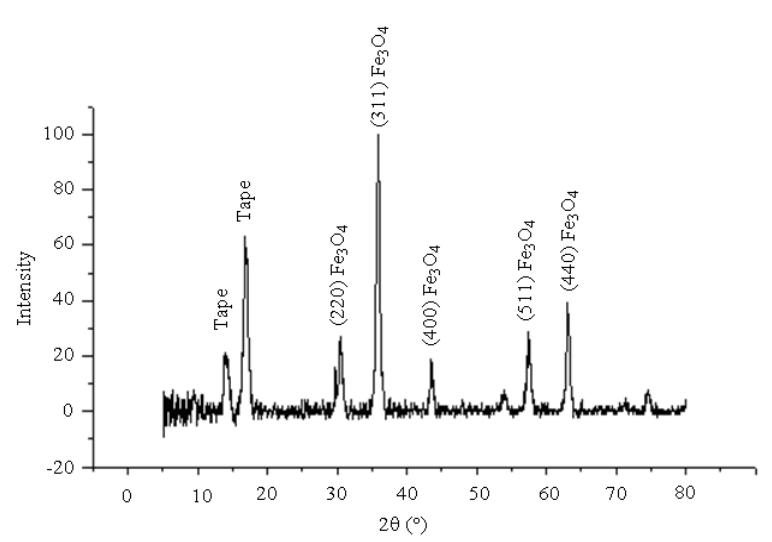

Fig. 2: XRD crystallographic pattern of SPIONs, fixed onto tape, at X-ray wavelength of $0.154 \mathrm{~nm}$ with $0.2^{\circ}$ steps of $2 \theta$

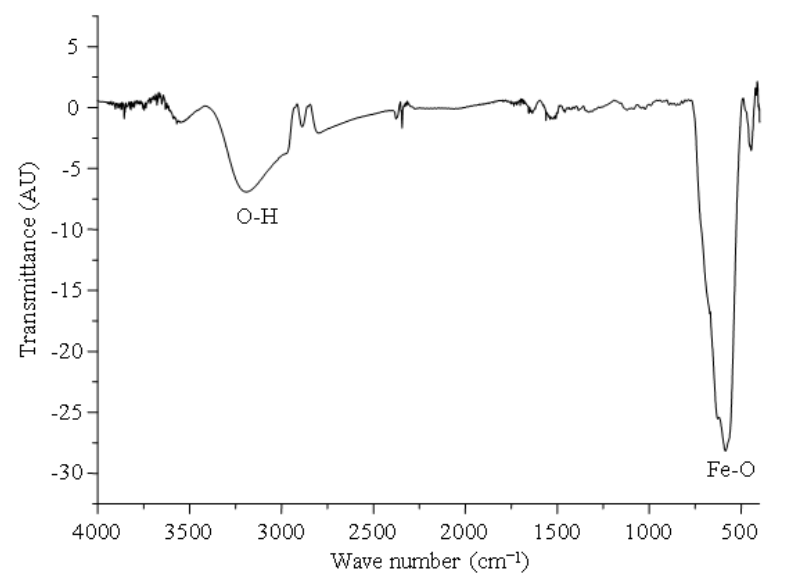

Fig. 3: FTIR graph of $\mathrm{Fe}_{3} \mathrm{O}_{4}$ magnetic nanoparticles synthesized by co-precipitation

Cytotoxicity study of SPIONs in macrophage and Chang liver cells: The purpose of this investigation was to evaluate potential toxicity and general mechanisms involved in SPIONs induced cytotoxicity, oxidative stress and pro-inflammatory response by MTT assay, TBARS assay and nitric oxide measurement investigated in an in vitro model derived from Chang liver cells or normal hepatocytes and macrophage cells. These cell lines have been well characterized for their relevance to toxicity studies and most concerns are about biodistribution of nanoparticles.

Cell viability after 24-h and 72-h exposure to SPIONs at $6.25,12.5,25,50$ and $100 \mu \mathrm{g} \mathrm{mL}^{-1}$ to macrophage and normal hepatocytes suggested a potential dose dependence as shown in Fig. 4, but results were not significantly different $(p>0.05)$.

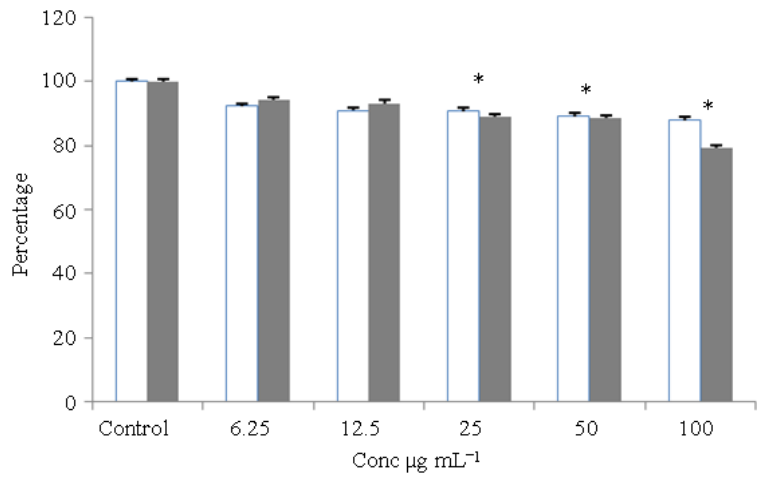

(a)

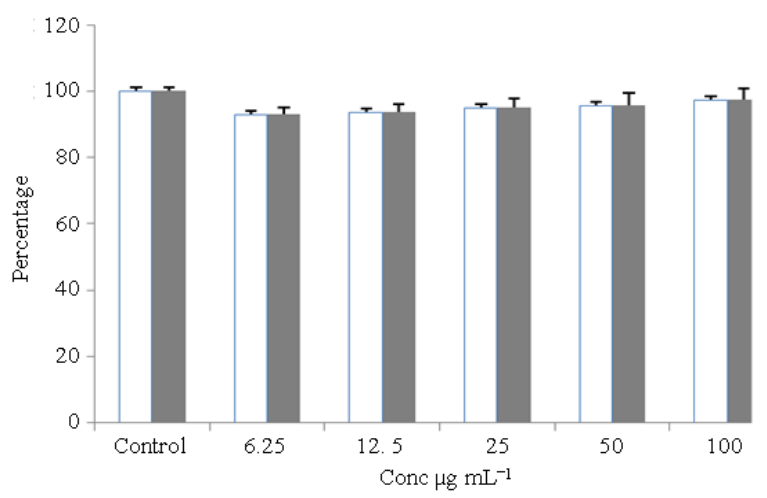

(b)

Fig. 4: Cell viability of (a) macrophage cells, (b) hepatocytes, after exposure to SPIONs assayed by MTT $(\mathrm{n}=8)$ after $24 \mathrm{~h}$ (blank columns) and $72 \mathrm{~h}$ (grey columns) $* \mathrm{p}<0.001$ analyzed by oneway ANOVA versus control groups

After $72 \mathrm{~h}$ exposure, however, the decrease was significant at a dose of higher than $25 \mu \mathrm{g} \mathrm{mL}^{-1}(\mathrm{p}<0.001)$, indicating a dose-dependent cytotoxicity of the SPIONs for macrophage cells. Thus, the macrophage cells and hepatocytes responded differently to the SPIONs. The presence of specific protein binding to iron of liver cells while macrophage cells uptake foreign particles via phagocytosis (Shubayev et al., 2009) might be the explanation of the different responses found in this study.

Iron oxide is a metal oxide which can oxidize certain cellular macromolecules including lipids, so TBARS was used to test this hypothesis after cellular exposure to SPIONs. Lipid peroxidation, a major indicator of oxidative stress and measured as TBARS, shown in Fig. 5, is dependent on the type of cells. With macrophage cells, Fig. 5a, a significant increase of TBARS was observed at $100 \mu \mathrm{g} \mathrm{mL} \mathrm{m}^{-1}(\mathrm{p}<0.05)$ after $24 \mathrm{~h}$; on the contrary, after $72 \mathrm{~h}$ at the same dose a decrease was observed, suggesting that cell adaptation occurred as a self-defense antioxidant 
response to oxidative stress. For normal liver cells, after 24 or $72 \mathrm{~h}$ of exposure to the SPIONs, no significantly change in lipid peroxidation was found (Fig. 5b). This study has further emphasized the effects of cell type, exposure duration and the nature of cell adaptations to the cytotoxicity.

Pro-inflammatory response was investigated using SPIONs as this was found with nanosized $\mathrm{TiO}_{2}$ and carbon black (Bhattacharya et al., 2009). Nitric oxide (NO) was measured as a signaling molecule vital to pathogenesis due to inflammation and usually overproduced in abnormal physiological conditions (Sharma et al., 1996). As a short-lived highly reactive and rapid diffusible molecule, its targets are numerous including iron clusters. Macrophage cells showed an increase in lipid peroxide susceptible to this effect. However, 24 and $72 \mathrm{~h}$ exposure to macrophage cells, SPIONs, up to $100 \mu \mathrm{g} \mathrm{mL}^{-1}$ did not significantly affect nitric oxide levels (Fig. 6) when compared to the control.

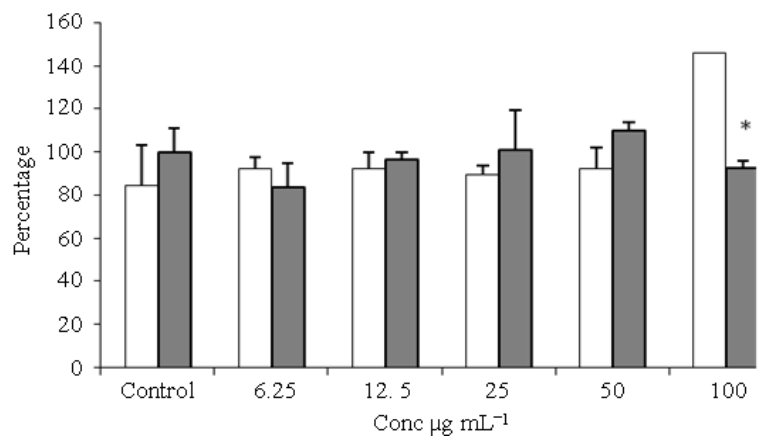

(a)

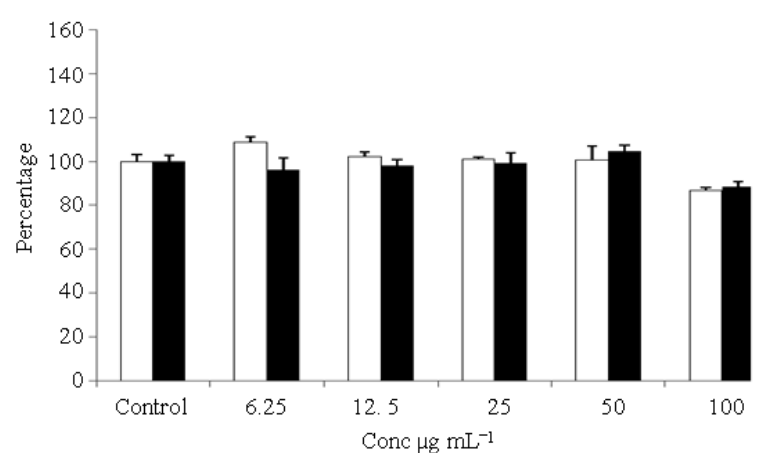

(b)

Fig. 5: Lipid peroxidation analyzed by cellular TBARS levels in (a) macrophage cells and (b) Chang liver cells after exposure to SPIONs for $24 \mathrm{~h}$ (blank columns) and $72 \mathrm{~h}$ (grey columns) $(\mathrm{n}=4-6) . * \mathrm{p}<0.05$ analyzed by one-way ANOVA versus control groups
Figure 7 illustrates microscopic changes of Chang liver cells exposed to various concentrations of SPIONs compared to a negative control. The result confirms that the SPIONs affect cells in a concentration dependent manner and at concentrations of higher than $25 \mu \mathrm{g}$ $\mathrm{mL}^{-1}$, cell deformation is observed.

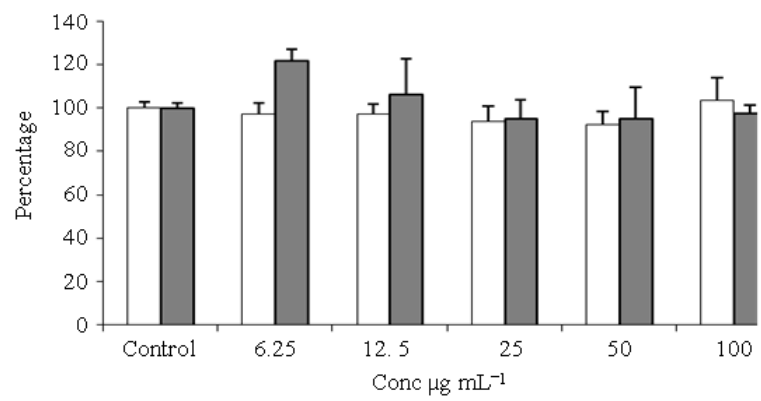

Fig. 6: Effects of SPIONs on nitric oxide level of macrophage cells after exposure for $24 \mathrm{~h}$ (blank columns) and $72 \mathrm{~h}$ (grey columns), analyzed using Griess reagent and reading the absorbance at $550 \mathrm{~nm}(\mathrm{n}=6)$
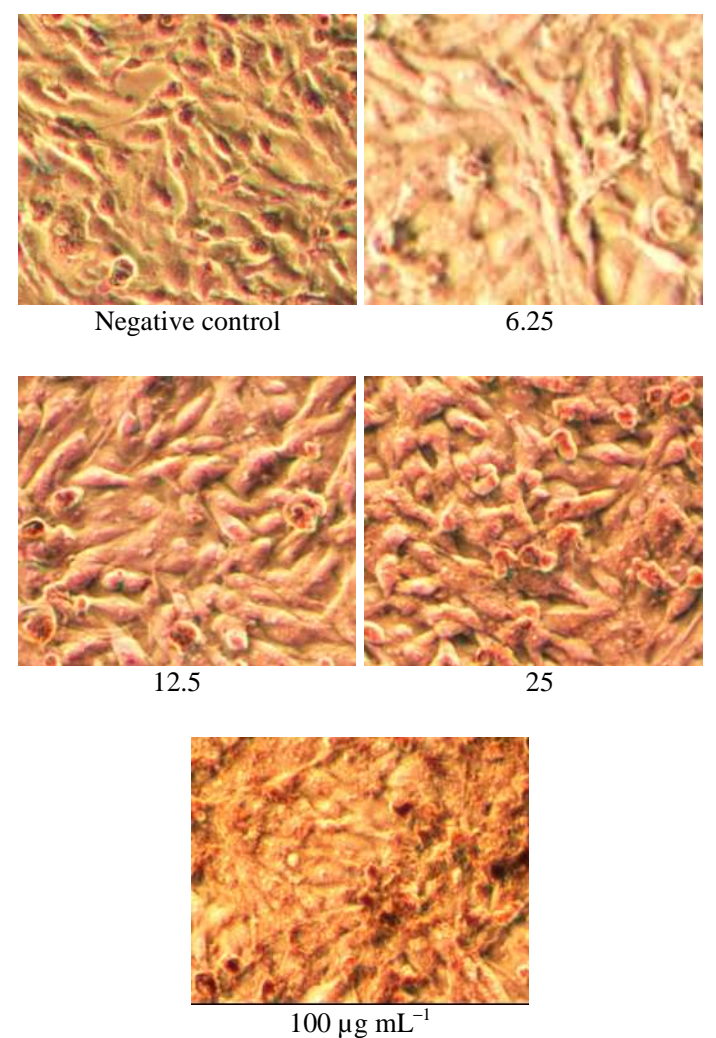

Fig. 7: Microscopic photographs of Chang liver cells exposed to SPIONs at various concentrations for $24 \mathrm{~h}(\times 100)$ 


\section{DISCUSSION}

The results from XRD and FTIR patterns suggest that the black precipitates obtained from our process are iron oxide of $\mathrm{Fe}_{3} \mathrm{O}_{4}$ or magnetite. The magnetite produced by this procedure shortens the NMR spin-spin relaxation time $\left(\mathrm{T}_{2}\right)$ of protons $\left({ }^{1} \mathrm{H}\right)$ of water containing the particles. Estimation of the relaxation rate, by equation (2), gave $1 / \mathrm{T}_{2}{ }^{*}$ of the SPIONs at $12.5,25,50$ and $100 \mathrm{~g} \mathrm{~mL}^{-1}$ of 22.6, 60.6, 136.6 and $279.0 \mathrm{sec}^{-1}$, respectively. Thus, an increase of the concentration of the particles also positively and linearly correlates with the relaxation rate $(r=0.9987)$. This indicates that the particles produced are SPIONs.

It has been shown that the size, shape and composition of nano-particle product depends on the type of salts used, the ratio of $\mathrm{Fe}^{2+}$ to $\mathrm{Fe}^{3+}, \mathrm{pH}$ and ionic strength of the media (Shubayev et al., 2009). A review (Gupta and Gupta, 2005) also suggests that the coprecipitation method used to produce SPIONs requires a non-oxidizing anaerobic environment while $\mathrm{Fe}^{2+}$ reacts with $\mathrm{Fe}^{3+}$ at a molar ratio of 1:2 and the black precipitates are to be expected at $\mathrm{pH} 9-14$. However, the process used in this study was different. The reaction was simple with an equivalent ratio of about 1:1 with aeration and a neutral $\mathrm{pH}$. The result of this simplified method has proven to be superparamagnetic iron oxide nanoparticles with saturation magnetization of $67.7 \mathrm{emu} \mathrm{g}^{-1}$ and coercivity of $34.5 \mathrm{G}$ by vibrating sample magnetometer.

The macrophage cells and hepatocytes responded differently to the SPIONs. The presence of specific proteins binding to the iron of liver cells, while macrophage cells take up foreign particles via phagocytosis (Shubayev et al., 2009), might be the explanation for the different responses found in this study. Previous reports have shown cellular oxidative stress by increased TBARS after exposure to nanoparticles such as $\mathrm{SiO}_{2}$ and fullerene $\mathrm{C}_{60}$. Using HEK293 cells, lipid peroxidation of $\mathrm{SiO}_{2}$ nanoparticles has been shown to be size-dependent (Wang et al., 2009). Fullerene $C_{60}$ significantly elevated lipid peroxidation and induced oxidative stress in a fish model (Oberdorster et al., 2006). This study has demonstrated that oxidative induction of nanoparticulates is concerned not only with cell type, but also the exposure duration and the nature of cell adaptations.

Results obtained from our current in vitro cytotoxicity study may not be a substitute for studies in vivo and that occur throughout the whole body. However, they give a basis for further assessing the potential risk of chemical /material exposure. As far as the assessment of toxicological properties of nanoparticles is concerned, it is not known how they behave when they are dispersed in exposure media. The method used in the preparation of the SPIONs in this study was shown to be simpler than the previous reports (Lee et al., 2008; Thorek et al., 2006; Teja and Koh, 2009; Verges et al., 2008), however some of the nanoparticles may rapidly agglomerate or settle and need constant stirring to make a homogeneous suspension, and so the full cellular dose/time of these materials would be larger. The other issue that is still not known is whether the cells internalize nanoparticles and if so, what are the mechanisms involved. Iron oxide as a metal oxide could oxidize certain cellular macromolecules including lipids, so TBARS was appropriate for measurement of this effect after cellular exposure to SPIONs. Our results from MTT assay, TBARS assay and NO measurement studies show that nanoparticles are associated with cytotoxicity, oxidative stress and lipid peroxidation formation but normal liver cells did not generate lipid peroxiation when exposed to $\leq 100 \mu \mathrm{g} \cdot \mathrm{mL}^{-1}$ of SPIONs. Cell adaptation was also observed as a self-defense antioxidant response to oxidative stress.

\section{CONCLUSION}

SPIONs were successfully prepared by a coprecipitation process with $\mathrm{pH}$ control at 7 and the optimum equivalent ratio of $\mathrm{Fe}^{3+}: \mathrm{Fe}^{2+}$ was $1: 1$. Materials which result in cell viabilities higher than $80 \%$ are often recognized as biocompatible, thus from the MTT assays conducted here, SPIONs produced by this method can be considered biocompatible, although they cause some cytotoxicity to both the cell types tested here at high concentrations. Furthermore, iron oxide nanoparticles did not induce oxidative stress and lipid peroxidation formation in Chang liver cells. Also, in macrophage cells at high initial concentration up to $100 \mu \mathrm{g} \mathrm{mL} L^{-1}$, using TBARS assay and nitric oxide measurement, SPIONs did not induce the release products of pro-inflammatory response from macrophage cells. However, the toxicity of iron oxide nanoparticles should be further investigated with other cells and other methods.

\section{ACKNOWLEDGEMENT}

The researchers would like to acknowledge the financial support of the National Research Council of Thailand (Grant no. PorKor/2552-84). Ms Nittaya Luenam, Ms Narissara Kulanaris and Ms Parichat Phothisai are thanked for their technical assistance. 


\section{REFERENCES}

Banaclocha, M.A.M., I. Bokkon and H.M. Banaclocha, 2010. Long-term memory in brain magnetite. Med. Hypotheses, 74: 254-257. DOI: 10.1016/j.mehy.2009.09.024

Bhaskar, S., F. Tian, T. Stoeger, W. Kreyling and J.M. de la Fuente et al., 2010. Multifunctional nanocarriers for diagnostics, drug delivery and targeted treatment across blood-brain barrier: Perspectives on tracking and neuroimaging. Part. Fibre Toxicol., 7: 1-3. DOI: 10.1186/1743-8977-73

Bhattacharya, K., M. Davoren, J. Boertz, R.P.E. Schins, E. Hoffmann and E. Dopp, 2009. Titanium dioxide nanoparticles induce oxidative stress and DNAadduct formation but not DNA-breakage in human lung cells. Part. Fiber Toxicol., 6: 17. DOI: 10.1186/1743-8977-6-17

Farrar, T.C. and E.D. Becker, 1971. Pulse and Fourier Transform NMR: Introduction to Theory and Methods. 1st Edn., Academic Press, New York, ISBN-10: 0122496507, pp: 118.

Gupta, A.K. and M. Gupta, 2005. Synthesis and surface engineering of iron oxide nanoparticles for biomedical applications. Biomaterials, 26: 39954021. PMID: 15626447

Jones, C.F. and D.W. Grainger, 2009. In vitro assesements of nanomaterial toxicity. Adv. Drug Deliv. Rev., 61: 438-456. DOI: 10.1016/j.addr.2009.03.005

Lee, Y.T., K. Woo and K. Choi, 2008. Preparation of water-dispersible and biocompatible iron oxide nanoparticles for MRI agent. IEEE $\mathrm{T}$. Nanotechnol., 7 : 111-114. DOI: 10.1109/TNANO.2007.909949

Ma, M., Y. Zhang, W. Yu, H. Shen, H. Zhang and N. $\mathrm{Gu}$, 2003. Preparation and characterization of magnetic nanoparticles coated by amino silane. Colloid Surf. A., 212: 219-226. DOI: 10.1016/S0927-7757(02)00305-9

Marques, R.F.C., C. Garcia, P. Lecante, S.J.L. Ribeiro and L. Noe et al., 2008. Electro-precipitation of $\mathrm{Fe}_{3} \mathrm{O}_{4}$ nanoparticles in ethanol. J. Magn. Magn. Mater., 320: 2311-2315. DOI: 10.1016/j.jmmm.2008.04.165

Molday, R.S., 1984. Magnetic iron-dextran microspheres. United States Patent 4452773, June 5. http://www.freepatentsonline.com/4452773.pdf

Oberdorster, E., S. Zhu, T.M. Blickley, P. McClellanGreen and M.L. Haasch, 2006. Ecotoxicology of carbon-based engineered nanoparticles: Effects of fullerene $\left(\mathrm{C}_{60}\right)$ on aquatic organisms. Carbon, 44: 1112-1120. DOI: 10.1016/j.carbon.2005.11.008

Ohkawa, H., N. Ohishi and K. Yagi, 1979. Assay for lipid peroxides in animal tissues by thiobarbituric acid reaction. Anal. Biochem., 95: 351-358. PMID: 36810

Pankhurst, Q.A., J. Connolly, S.K. Jones and J. Dobson, 2003. Applications of magnetic nanoparticles in biomedicine. J. Phys. D Appl. Phys., 36: R167-R181. http://www.physics.gla.ac.uk/ dtngo/Article/JPD_ 36_2003_R167.pdf

Papell, S.S., 1965. Low viscosity magnetic fluid obtained by the colloidal suspension of magnetic particles. United States Patent 3215572, November 2. http://www.freepatentsonline.com/3215572.pdf

Pei, W., H. Kumada, T. Natusme, H. Saito and S. Ishio, 2007. Study on magnetite nanoparticles synthesized by chemical method. J. Magn. Magn. Mater., 310: 2375-2377. DOI: 10.1016/j.jmmm.2006.10.837

Sharma, H.S., J. Westman, Y. Olsson and P. Alm, 1996. Involvement of nitric oxide in acute spinal cord injury: An immunocytochemical study using light and electron microscopy in the rat. Neurosci. Res., 24: 373-384. DOI: 10.1016/01680102(95)01015-7

Shubayev, V.I., T.R. Pisanic and S. Jin, 2009. Magnetic nanoparticles for theragnostics. Adv. Drug Deliv. Rev., 61: 467-477. DOI: 10.1016/j.addr.2009.03.007

Sun, C., J. Lee and M. Zhang, 2008. Magnetic nanoparticles in NMR imaging and drug delivery. Adv. Drug Deliv. Rev., 60: 1252-1265. DOI: 10.1016/j.addr.2008.03.018

Sun, S. and H. Zeng, 2002. Size-controlled synthesis of magnetite nanoparticles. J. Am. Chem Soc., 124: 8204-8205. DOI: 10.1021/ja026501x

Teja, A.S. and P.Y. Koh, 2009. Synthesis, properties and applications of magnetic iron oxide nanoparticles. Prog. Cryst. Growth Ch., 55: 22-45. DOI: 10.1016/j.pcrysgrow.2008.08.003

Thorek, D.L., A.K. Chen, J. Czypryna and A. Tsourkas, 2006. Superparamagnetic iron oxide nanoparticle probes for molecular imaging. Ann. Biomed. Eng., 34: 23-38. PMID: 16496086

Verges, M.A., R. Costo, A.G. Roca, J.F. Marco and G.F. Goya et al., 2008. Uniform and water stable magnetite nanoparticles with diameters around the monodomain-multidomain limit. J. Phys. D Appl. Phys., 41: 134003. DOI: 10.1088/0022$3727 / 41 / 13 / 134003$ 
Wang, F., F. Gao, M. Lan, H. Yuan, Y. Huang and J. Liu, 2009. Oxidative stress contributes to silica nanoparticle-induced cytotoxicity in human embryonic kidney cells. Toxicol. In Vitro, 23: 808815. DOI: 10.1016/j.tiv.2009.04.009

Wang, J., J. Sun, Q. Sun and Q. Chen, 2003. One-step hydrothermal process to prepare highly crystalline $\mathrm{Fe}_{3} \mathrm{O}_{4}$ nanoparticles with improved magnetic properties. Mater. Res. Bull., 38: 1113-1118. DOI: 10.1016/S0025-5408(03)00129-6
Wang, X., C. Zhang, X. Wang and H. Gu, 2007. The study on magnetite particles coated with bilayer surfactants. Appl. Surf. Sci., 253: 7516-7521. DOI: 10.1016/j.apsusc.2007.03.053

Xu, C. and A.S. Teja, 2008. Continuous hydrothermal synthesis of iron oxide and PVA-protected iron oxide nanoparticles. J. Supercrit. Fluid., 44: 85-91. DOI: 10.1016/j.supflu.2007.09.033 